\title{
ORIGINAL ARTICLE \\ Cost-effectiveness analysis of telephone-based support for the management of pressure ulcers in people with spinal cord injury in India and Bangladesh
}

\author{
M Arora ${ }^{1,2}$, LA Harvey ${ }^{1,2}$, JV Glinsky ${ }^{1,2}$, HS Chhabra ${ }^{3}$, MS Hossain ${ }^{4}$, N Arumugam ${ }^{5}$, PK Bedi ${ }^{5}$, ID Cameron ${ }^{1,2}$ \\ and AJ Hayes ${ }^{6}$
}

Objective: To determine from a societal perspective the cost-effectiveness and cost-utility of telephone-based support for management of pressure ulcers.

Study design: Cost-effectiveness and cost-utility analysis of a randomised clinical trial.

Setting: Tertiary centre in India and Bangladesh.

Methods: An economic evaluation was conducted alongside a randomised clinical trial comparing 12 weeks of telephone-based support (intervention group) with usual care (control group). The analyses evaluated costs and health outcomes in terms of $\mathrm{cm}^{2}$ reduction of pressure ulcers size and quality-adjusted life years (QALYs) gained. All costs were in Indian Rupees (INR) and then converted to US dollars (USD).

Results: The mean (95\% confidence interval) between-group difference for the reduction in size of pressure ulcers was 0.53 (-3.12 to 4.32) $\mathrm{cm}^{2}$, favouring the intervention group. The corresponding QALYs were $0.027(0.004-0.051)$, favouring the intervention group. The mean total cost per participant in the intervention group was INR 43781 (USD 2460) compared to INR 42561 (USD 2391) for the control group. The per participant cost of delivering the intervention was INR 2110 (USD 119). The incremental cost-effectiveness ratio was INR 2306 (USD 130) per additional $\mathrm{cm}^{2}$ reduction in the size of the pressure ulcer and INR 44915 (USD 2523) per QALY gained.

Conclusion: In terms of QALYs, telephone-based support to help people manage pressure ulcers at home provides good value for money and has an $87 \%$ probability of being cost-effective, based on 3 times gross domestic product. Sensitivity analyses were performed using the overall cost data with and without productivity costs, and did not alter this conclusion.

Spinal Cord (2017) 55, 1071-1078; doi:10.1038/sc.2017.87; published online 15 August 2017

\section{INTRODUCTION}

Pressure ulcers are a major complication of spinal cord injury (SCI) particularly in low- and middle-income countries (LMICs). ${ }^{1,2}$ They are associated with serious consequences and can lead to functional limitations affecting a person's family and social life as well as healthrelated quality of life. ${ }^{3}$ Importantly, they are a major cause of mortality. For example, a large cohort study from Bangladesh found that one in five wheelchair-dependent people discharged from hospital following SCI had died within 2 years: predominantly from pressure ulcers. $^{4}$

There is a big difference between management of pressure ulcers for people in high-income countries and LMICs. ${ }^{5}$ In high-income countries, treatment is usually intensive and includes education, debridement, costly equipment, sophisticated dressings, specialised diets, and physical therapies delivered by members of a multidisciplinary team. ${ }^{6,7}$ However, such resources and services are not commonly available in LMICs like India and Bangladesh, where patients are largely left to manage their pressure ulcers alone and at home, and care is primarily funded by the individual. There is a pressing need to address the problem of pressure ulcers in LMICs with interventions that are not cost prohibitive.

We hypothesised that regular telephone-based support might be an inexpensive way of helping people manage their pressure ulcers at home in LMICs. Therefore, between 2014 and 2016, we conducted a randomised controlled trial to evaluate the effectiveness of 12 weeks of telephone-based support compared to usual care for the treatment of pressure ulcers in people with SCI. ${ }^{8}$ The effectiveness data are published elsewhere but in brief, the intervention resulted in a reduction of the pressure ulcers compared to control but this result was not statistically significant $(P=0.08)$. The results of eight of the 13 secondary outcomes were however both statistically significant and potentially clinically important. These outcomes included the Pressure Ulcer Scale for Healing, Braden Scale, WHO Disability Assessment Scale (participation items), EQ-5D (utility and health score), time for pressure ulcer resolution, participants' confidence managing pressure ulcers, and participants' satisfaction with healthcare provision.

\footnotetext{
1John Walsh Centre for Rehabilitation Research, Kolling Institute of Medical Research, Northern Sydney Local Health District, St Leonards, New South Wales, Australia; ${ }^{2}$ Sydney Medical School Northern, The University of Sydney, Sydney, New South Wales, Australia; ${ }^{3}$ Department of Spine Service, Indian Spinal Injuries Centre, Delhi, India; ${ }^{4}$ Centre for Rehabilitation of the Paralysed, Savar, Bangladesh; ${ }^{5}$ Department of Physiotherapy, Punjabi University, Patiala, India and ${ }^{6}$ School of Public Health, The University of Sydney, Sydney, New South Wales, Australia

Correspondence: Dr Mohit Arora, John Walsh Centre for Rehabilitation Research, Level 13, Kolling Institute of Medical Research, Royal North Shore Hospital, St Leonards, New South Wales 2065, Australia.

E-mail: mohit.arora@sydney.edu.au

Received 15 February 2017; revised 16 June 2017; accepted 20 June 2017; published online 15 August 2017
} 
An important associated question was whether this intervention was cost-effective. Cost-effectiveness analyses are rarely conducted alongside clinical trials involving people with spinal cord injury yet they are essential for policy and decision makers particularly in LMICs where the healthcare resources are so limited. A few studies from highincome countries have started to look at the cost-effectiveness of different interventions for the management of pressure ulcers, ${ }^{9-11}$ but the findings are not particularly relevant to LMICs. The aim therefore of the present study was to examine the cost-effectiveness and costutility of the telephone-based support for the management of pressure ulcers in people with SCI in India and Bangladesh.

\section{MATERIALS AND METHODS}

We conducted an economic evaluation of a multicenter, prospective, assessorblinded, parallel, pragmatic, randomised controlled trial. The societal perspective was adopted for this economic evaluation because the cost consequences of this intervention extend beyond the domain of health care. In addition, the societal perspective estimates the broader costs to society and includes direct medical costs, direct non-medical costs, and indirect costs. These costs were divided into three sub-headings including cost of delivering the intervention, healthcare (direct medical and direct non-medical) costs and productivity (indirect) costs.

The study was conducted from three sites in India and Bangladesh. The study was approved by the Institutional Ethics Committee at each site and all participants gave their consent before participating in the study. The study was prospectively registered at the Australian New Zealand Clinical Trial Registry (Identifier- ACTRN12613001225707). The study protocol is published elsewhere and is freely available. ${ }^{12}$ The clinical results of the study have also been published. ${ }^{8}$ This paper solely focuses on the economic evaluation.

\section{Participants}

Participants were recruited from outpatient clinics and through hospital databases. Participants were included if they were aged 18 years or more, had sustained an SCI 3 months prior to recruitment, had at least one pressure ulcer (on the sacrum, ischial tuberosity or greater trochanter of the femur) and were living in the community. Participants were excluded if they had cognitive or verbal impairments, or had any clinically significant medical condition that would compromise participation in the trial.

\section{Intervention}

In brief, participants were randomly allocated to the control or intervention group. Participants in both groups received usual care. This typically involved participants managing their pressure ulcers by themselves or with the help of family members at home. Participants were free to seek any other type of help or medical assistance that they deemed appropriate or had access to. In addition, participants in the intervention group received weekly telephone support (call duration 15-25 min) over 12 weeks from an appropriately trained healthcare professional. During each telephone call, the healthcare professional reinforced self-help strategies important for managing pressure ulcers, minimising psychological stress and enhancing engagement with life. This included education and advice about appropriate seating, bed overlays, cushions, equipment, diet, nutrition and wound dressings. In addition, participants and their family members were advised about techniques to relieve pressure and when to seek further medical or nursing attention. Participants were also given advice on any other related issues which may be contributing to the pressure ulcer (for example, bladder or bowel incontinence, spasticity, depression). Goals were set in consultation with participants for each week and subsequently reviewed, monitored and updated. For example, a goal might have included staying on strict bed rest for the next week.

\section{Measurement of health outcomes \\ The health outcome measures used for the economic evaluation were:}

Reduction in the size of pressure ulcer at 12 weeks. This was assessed using commercially available grid paper designed for this purpose. Length and width were measured, and pressure ulcer size was expressed as $\mathrm{cm}^{2}$. Reduction in pressure ulcer size per partcipant was determined from pressure ulcer size at 12 weeks minus pressure ulcer size at baseline.

Quality-adjusted life years (QALYs). Quality of life was measured using the Euro Quality of Life-5 Dimensional-5 level (EQ-5D-5L) health survey administered at baseline and 12 weeks. Participants' health states were captured using the 5 domains of the EQ-5D-5L namely, mobility, self-care, usual activities, pain/discomfort and anxiety/depression. The EQ-5D-5L was mapped to the Euro Quality of Life-5 Dimensional-3 level (EQ-5D-3L) using the crosswalk method. ${ }^{13}$ The reponses on each domain were converted to utility weights for each participant using the Sri Lankan valuation of the EQ-5D-3L. ${ }^{14}$ Then the average of the baseline and 12-week utility score weights for participants in both groups were multiplied by the time period (12/52 weeks) to derive QALYs. Incremental QALYs were then computed as the difference in mean QALYs (intervention group minus control group).

\section{Measurement and valuation of resource use}

Participants in both groups were given diaries to record items that they purchased (that is, resource items) and the time spent on different activities related to the treatment of their pressure ulcers over the 12-week study period. They were contacted once every fortnight to take a verbal transcript from their diaries. In addition, the costs of delivering the intervention, as part of the study, were also collected. The overall costs were then put into three sub-headings, namely-cost of delivering the intervention, healthcare costs and productivity costs as detailed below.

Cost of delivering the intervention. This included costs incurred by the study to employ healthcare professionals and administrators, as well as the cost of the telephone calls and travel.

Healthcare cost. This included costs incurred by the participants to purchase equipment and resources to manage their pressure ulcer such as beds, mattresses, wheelchairs, pressure-relieving cushions, medical consultations, transportation, medications, medical supplies, dressings, special high-protein food, lotions and

Table 1 Baseline characteristics of participants included in the costeffectiveness analysis

\begin{tabular}{lcc}
\hline Participant characteristics & Intervention $(\mathrm{n}=57)$ & Control $(\mathrm{n}=58)$ \\
\hline Age (years), mean (s.d.) & $35(11)$ & $36(12)$ \\
& & \\
Gender, $\mathrm{n}(\%)$ & $52(87)$ & $54(90)$ \\
Male & $8(13)$ & $6(10)$ \\
$\quad$ Female & $3.7(1.4,9.6)$ & $3.7(1.3,8.5)$
\end{tabular}

median (IQR)

Location of PU, n (\%)

Sacral

29 (48)

$25(42)$

Right ischial tuberosity

$10(17)$

Left ischial tuberosity

$13(22)$

$12(20)$

Right trochanter of the femur

$10(17)$

8 (13)

Left trochanter of the femur

2 (3)

$5(8)$

Stage of $P U, \mathrm{n}(\%)$

Stage II

22 (37)

$13(22)$

Stage III

38 (63)

Stage IV

Size of PU, mean (s.d.)

$9.2(11.6)$

$12.5(13.2)$

Utility score-EQ-5D-5L, mean (s.d.)

(100 points), mean (s.d.)

Abbreviations: EQ-5D-5L, Euro Quality of Life -5 Dimensional— 5 level; IQR, Inter quartile range; PU, pressure ulcers; VAS, Visual Analogue Scale. 
Table 2 Cost of delivering the telephone intervention per participant over 12 weeks in Indian Rupee (INR) for the year 2015

\begin{tabular}{|c|c|c|c|c|c|}
\hline Items & $\begin{array}{l}\text { Unit cost, INR } \\
\text { per unit }\end{array}$ & $\begin{array}{l}\text { Resource } \\
\text { use }\end{array}$ & $\begin{array}{l}\text { Participants, } \\
\text { n (\%) }\end{array}$ & $\begin{array}{l}\text { Total cost, } \\
\text { INR }\end{array}$ & Source of unit costing \\
\hline $\begin{array}{l}\text { Telephone calls (call of } \\
16 \text { min duration } \\
\text { per participant) }\end{array}$ & 16 per call & 12 & $57(100)$ & 10944 & $\begin{array}{l}\text { The cost of a local call. Each participant received } 12 \text { calls in } 12 \text { weeks. } \\
\text { http://delhi.mtnl.net.in/commercial/tariff_delhi.htm (accessed on } 04 \\
\text { October 2016) }\end{array}$ \\
\hline $\begin{array}{l}\text { Health professionals' } \\
\text { time (to deliver } \\
\text { telephone-based } \\
\text { management per } \\
\text { participant) }\end{array}$ & 234.6 per hour & 5.1 & $57(100)$ & 68198 & $\begin{array}{l}\text { Based on the cost of a full time appropriately trained health care } \\
\text { professional (INR } 45035 \text { per month). This included calling time and } \\
\text { case management time of } 10 \text { min per call. http://mof.gov.in/6cpc/ } \\
\text { 6cpcreport.pdf (accessed on } 04 \text { October 2016) }\end{array}$ \\
\hline $\begin{array}{l}\text { Administrators' time (to } \\
\text { arrange telephone calls, } \\
\text { print material and other } \\
\text { related work per } \\
\text { participant) }\end{array}$ & 135.1 per hour & 2 & $57(100)$ & 15401 & $\begin{array}{l}\text { The cost of an administrator (INR } 25932 \text { per month). http://www.ilbs. } \\
\text { in/index.php?option = com_content\&view = article\&id=367\& Itemid = } \\
56 \text { (accessed on } 04 \text { October 2016) }\end{array}$ \\
\hline $\begin{array}{l}\text { Trainers' time (to provide } \\
\text { training to healthcare } \\
\text { professionals) }\end{array}$ & & & & & $\begin{array}{l}\text { The cost is based on the monthly salary of an allied healthcare professional } \\
\text { (which includes a nurse; dietician; physiotherapist; occupational therapist } \\
\text { (INR } 45035 \text { per month)) and medical consultant (INR } 203718 \text { per }\end{array}$ \\
\hline $\begin{array}{l}\text { a. Allied healthcare } \\
\text { professional }\end{array}$ & 234.6 per hour & 31 & - & 7273 & $\begin{array}{l}\text { month) http://www.ilbs.in/index.php?option =com_content\&view = } \\
\text { article\&id =367\&ltemid = } 56 \text { (accessed on } 04 \text { October 2016) }\end{array}$ \\
\hline b. Medical consultant & 1061 per hour & 5 & - & 5305 & \\
\hline $\begin{array}{l}\text { Health professionals' } \\
\text { time (to attend training) }\end{array}$ & 234.6 per hour & 36 & - & 8445 & $\begin{array}{l}\text { The cost of one health care professional. } \\
20 \mathrm{~h}=\text { Self-training plus } 36 \mathrm{~h} \text { with instructors (INR } 45035 \text { per month). }\end{array}$ \\
\hline $\begin{array}{l}\text { Health professionals' } \\
\text { time (self-training) }\end{array}$ & 234.6 per hour & 20 & - & 4692 & $\begin{array}{l}\text { http://www.ilbs.in/index.php?option = com_content\&view = article\&id = } \\
\text { 367\&ltemid = } 56 \text { (accessed on } 04 \text { October 2016) }\end{array}$ \\
\hline & & \multicolumn{2}{|c|}{$\begin{array}{l}\text { Telephone intervention cost } \\
\text { Telephone intervention } \\
\text { cost per participant }\end{array}$} & $\begin{array}{l}120259 \\
2110\end{array}$ & \\
\hline
\end{tabular}

incontinence aids. This also included costs associated with hospitalisation, travel, nursing care and other care.

Productivity cost. This included costs incurred by the participants and families associated with missing work because of the pressure ulcer. For example, the lost income of a participant unable to work because of prolonged bed rest.

Price or unit costs were applied to the mean resource utilisation to translate the resources used by the participant into monetary values. Resources were valued either from market prices (local or national costs) or if unavailable, from the mean costs recorded in participants' diaries. Discounting was not applied as the time horizon was limited to three months.

Costs were valued for the year 2015 and expressed as Indian Rupee (INR) and USD. The conversions from INR to USD were done using the purchasing power parity method (that is, $1 \mathrm{USD}=\mathrm{INR} 17.8$ ) for the year $2015 .{ }^{15}$

\section{Cost-effectiveness analysis}

Incremental cost-effective ratios (ICERs) were calculated for reduction in pressure ulcer size and QALYs gained. Each ICER was calculated by dividing the difference in per participant mean cost (intervention minus control) by the difference in outcome measures (Equation 1).

$$
\text { ICER }=\frac{\text { Cost of intervention group }- \text { Cost of control group }}{\text { Outcome of intervention group }- \text { Outcome of control group }}
$$

(Equation 1)

Bootstrapping methods (using 1000 replications with replacement) were used to examine the joint probability distribution of costs and outcomes. Bootstrapped costs and outcome pairs were graphically displayed as a scatter plot on an incremental cost-effectiveness plane. ${ }^{16,17}$

Cost-effectiveness acceptability curves (CEAC) were derived to determine the probability that the intervention is cost-effective given a decision maker's willingness to pay for improvements in pressure ulcer size and QALYs. The ICER were interpreted according to the approach recommended by The
Commission for Macro-Economics on Health. ${ }^{18}$ This approach recommended that for the interpretation of ICER on CEAC, an intervention is considered to be 'cost-effective' if the ICER is less than three times per capita national gross domestic product (GDP). India had a GDP per capita of INR 110553 (USD 1808) in $2015 .{ }^{19}$ Sensitivity analysis included consideration of the total cost of the intervention with and without productivity costs included. Bootstrap sampling of costs and effects were repeated for this sensitivity analysis, and ICERs and CEAC were recalculated.

\section{Statistical analysis}

Descriptive data were provided as mean (SD) or counts (percentages), as appropriate (Table 1). In the primary paper, clinical effectiveness was reported as the mean $(95 \% \mathrm{CI})$ between-group difference for the size of pressure ulcers $\left(2.33 \mathrm{~cm}^{2} ; 95 \% \mathrm{CI}-0.3\right.$ to 4.9$)$ and was analysed using linear regression with baseline pressure ulcer size and group allocation as covariates. ${ }^{8}$ However, for this economic evaluation, the mean between group difference was calculated from the change data (that is, difference between the baseline and follow-up size of pressure ulcer) and the $95 \%$ CI was calculated using bootstrapping techniques. Hence, the mean between group difference and 95\% CI reported in this paper is slightly different to the corresponding values in the primary paper reporting clinical effectiveness. All statistical and cost-effectiveness analyses were performed using STATA software (version 11, StataCorp LP, Texas, USA).

\section{RESULTS}

Overall, one hundred and twenty people with pressure ulcers secondary to SCI were recruited. Five participants (3 in the intervention group; 2 in the control group) were excluded from the economic evaluation because they dropped out of the trial prior to the 12-week assessment. The participants' characteristics were similar at baseline for both groups (Table 1). 
Table 3 Health care costs and productivity costs per participant over 12 weeks in Indian Rupee (INR) for the year 2015, by intervention and control group

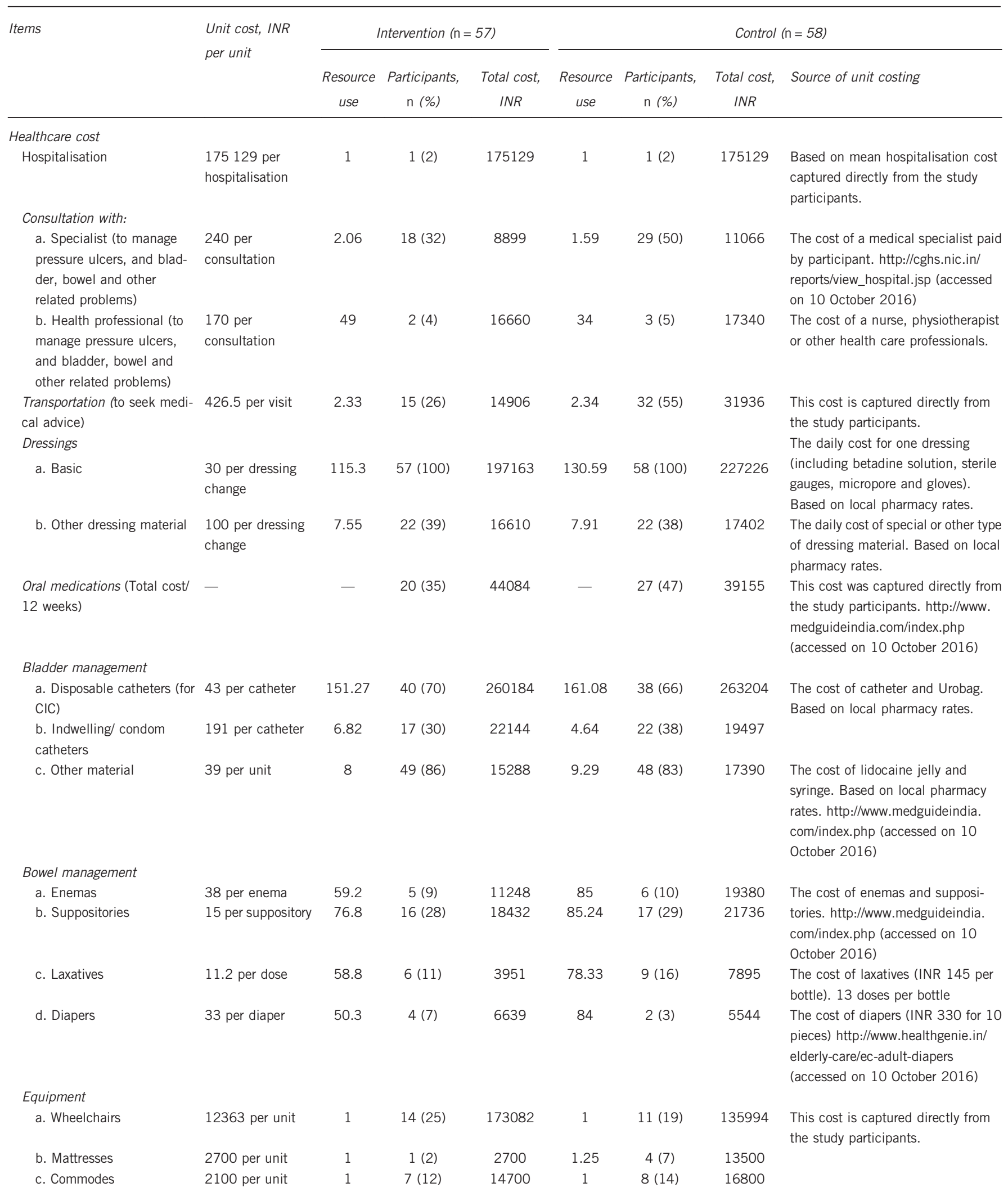


Table 3 (Continued)

\begin{tabular}{|c|c|c|c|c|c|c|c|c|}
\hline \multirow[t]{2}{*}{ Items } & \multirow{2}{*}{$\begin{array}{l}\text { Unit cost, INR } \\
\text { per unit }\end{array}$} & \multicolumn{3}{|c|}{ Intervention $(\mathrm{n}=57)$} & \multicolumn{4}{|c|}{ Control $(\mathrm{n}=58)$} \\
\hline & & $\begin{array}{c}\text { Resource } \\
\text { use }\end{array}$ & $\begin{array}{c}\text { Participants, } \\
\text { n (\%) }\end{array}$ & $\begin{array}{l}\text { Total cost, } \\
\text { INR }\end{array}$ & $\begin{array}{c}\text { Resource } \\
\text { use }\end{array}$ & $\begin{array}{c}\text { Participants, } \\
\text { n (\%) }\end{array}$ & $\begin{array}{l}\text { Total cost, } \\
\text { INR }\end{array}$ & Source of unit costing \\
\hline Diet and Nutrition & 45 per meal & 29.16 & $57(100)$ & 74795 & 25.33 & $51(88)$ & 58132 & $\begin{array}{l}\text { The cost of one portion of meat (INR } \\
25 \text { per meal), milk ( } 10 \text { per serve), } \\
\text { egg ( } 10 \text { for } 2 \text { eggs) https://www. } \\
\text { numbeo.com/food-prices/ (accessed } \\
\text { on } 10 \text { October 2016) }\end{array}$ \\
\hline \multirow[t]{3}{*}{$\begin{array}{l}\text { Carers- time spent for pres- } \\
\text { sure ulcer care }\end{array}$} & 55.5 per hour & 195 & $5(9)$ & 54112 & 225 & $6(10)$ & 74925 & $\begin{array}{l}\text { The cost of carers' time for participant } \\
\text { care. INR 20,000 per month http:// } \\
\text { www.medcareathome.com/index.html } \\
\text { (accessed on } 10 \text { October 2016) }\end{array}$ \\
\hline & & \multicolumn{2}{|c|}{ Healthcare cost } & 1130729 & \multicolumn{2}{|c|}{ Healthcare cost } & 1173257 & \\
\hline & & \multicolumn{2}{|c|}{$\begin{array}{l}\text { Healthcare cost per } \\
\text { participant }\end{array}$} & 19837 & \multicolumn{2}{|c|}{$\begin{array}{l}\text { Healthcare cost per } \\
\text { participant }\end{array}$} & 20229 & \\
\hline \multicolumn{9}{|c|}{ Productivity cost (participant and carer time input to treatment) } \\
\hline $\begin{array}{l}\text { Personal cost- time spent for } \\
\text { pressure ulcer care }\end{array}$ & 49.8 per hour & 190.1 & $57(100)$ & 539617 & 185.38 & $58(100)$ & 535451 & $\begin{array}{l}\text { The cost of participants' time for } \\
\text { personal care based on Labour } \\
\text { wages (INR } 9568 \text { per month). http:// } \\
\text { www.delhi.gov.in/wps/wcm/connect/ } \\
\text { doit_labour/Labour/Home/ (accessed } \\
\text { on } 10 \text { October 2016) }\end{array}$ \\
\hline $\begin{array}{l}\text { Participant's travel time (to } \\
\text { seek medical advice) }\end{array}$ & 49.8 per hour & 2.56 & $15(26)$ & 1912 & 2.73 & $33(57)$ & 4486 & $\begin{array}{l}\text { The cost of time lost during travel } \\
\text { based on labour wages (INR } 9568 \\
\text { per month). http://www.delhi.gov.in/ } \\
\text { wps/wcm/connect/doit_labour/ } \\
\text { Labour/Home/ (accessed on } 10 \\
\text { October 2016) }\end{array}$ \\
\hline \multirow[t]{3}{*}{$\begin{array}{l}\text { Family member or friend cost- } \\
\text { time spent for pressure ulcer } \\
\text { care }\end{array}$} & 49.8 per hour & 247.65 & $57(100)$ & 702979 & 270.84 & $56(97)$ & 755318 & $\begin{array}{l}\text { The cost of family members' time for } \\
\text { participant care; Labour wages (INR } \\
9568 \text { per month). http://www.delhi. } \\
\text { gov.in/wps/wcm/connect/doit_labour/ } \\
\text { Labour/Home/ (accessed on } 10 \\
\text { October 2016) }\end{array}$ \\
\hline & & \multirow{2}{*}{\multicolumn{2}{|c|}{$\begin{array}{l}\text { Productivity cost } \\
\text { Productivity cost per } \\
\text { participant }\end{array}$}} & 1244509 & \multirow{2}{*}{\multicolumn{2}{|c|}{$\begin{array}{l}\text { Productivity cost } \\
\text { Productivity cost per } \\
\text { participant }\end{array}$}} & 1295257 & \\
\hline & & & & 21833 & & & 22332 & \\
\hline
\end{tabular}

Abbreviation: CIC, Clean Intermittent Catheterisation.

Table 4 Cost of Intervention, healthcare and productivity costs, by intervention and control

\begin{tabular}{|c|c|c|c|c|c|c|c|c|}
\hline \multirow[t]{2}{*}{ Items } & \multicolumn{4}{|c|}{ Intervention $(\mathrm{n}=57)$} & \multicolumn{4}{|c|}{ Control $(n=58)$} \\
\hline & $\begin{array}{l}\text { Per participant cost } \\
\text { (INR), mean (s.d.) }\end{array}$ & $\begin{array}{l}\text { Per participant cost } \\
\text { (USD), mean (s.d.) }\end{array}$ & $\begin{array}{l}\text { Total cost } \\
\text { (INR) }\end{array}$ & $\begin{array}{l}\text { Total cost } \\
\text { (USD) }\end{array}$ & $\begin{array}{l}\text { Per participant cost } \\
\text { (INR), mean (s.d.) }\end{array}$ & $\begin{array}{l}\text { Per participant cost } \\
\text { (USD), mean (s.d.) }\end{array}$ & $\begin{array}{c}\text { Total cost } \\
\text { (INR) }\end{array}$ & $\begin{array}{c}\text { Total cost } \\
\text { (USD) }\end{array}$ \\
\hline $\begin{array}{l}\text { Telephone } \\
\text { intervention }\end{array}$ & $2110(0)$ & $119(0)$ & 120259 & 6756 & $0(0)$ & $0(0)$ & 0 & 0 \\
\hline Healthcare cost & 19837 (30 471) & $1114(1712)$ & 1130729 & 63524 & 20229 (26 209) & 1136 (1472) & 1173257 & 65913 \\
\hline Productivity cost & 21833 (3770) & 1227 (212) & 1244509 & 69916 & 22332 (4375) & $1255(246)$ & 1295257 & 72767 \\
\hline Overall cost & 43781 (28 721) & 2460 (1614) & 2495497 & 140196 & 42561 (25 819) & 2391 (1451) & 2468513 & 138681 \\
\hline
\end{tabular}

Abbreviations: INR, Indian Rupee; USD, US Dollars. 
Cost of delivering the intervention. Table 2 details the costs of delivering the intervention over 12 weeks and includes the total costs and the per participant cost of delivering the intervention. The total cost of delivering the intervention was INR 120259 (USD 6756). The cost per partcipant was INR 2110 (USD 119).

Healthcare cost. Table 3 details the healthcare costs over 12 weeks and includes the total healthcare costs and the per participant healthcare cost. The total healthcare costs in the intervention and control groups for the 12 weeks were INR 1130729 (USD 63 524) and INR 1173257 (USD 65 913), respectively. The mean total healthcare cost per participant was INR 19837 (USD 1114) in the intervention group and INR 20229 (USD 1136) in the control group.

Productivity cost. Table 3 also details the productivity costs over 12 weeks and includes the total productivity costs and the per participant productivity cost. The total productivity costs in the intervention and control groups for the 12 weeks were INR 1244509 (USD 69 916) and INR 1295257 (USD 72 767), respectively. The mean total productivity cost per person was INR 21833 (USD 1227) in the intervention group and INR 22332 (USD 1255) in the control group. The productivity cost was the major component for both groups.

Overall costs. The overall costs in intervention and control groups for the 12 weeks were INR 2495497 (USD 140 196) and INR 2468513 (USD 138681 ), respectively. The mean overall per person cost was INR 43781 (USD 2460) in the intervention group and INR 42561 (USD 2391) in the control group (Table 4).

\section{Health outcomes}

The results of the health outcomes are provided in Table 5. The mean between-group difference $(95 \% \mathrm{CI})$ in pressure ulcer size reduction was $0.53 \mathrm{~cm}^{2}$ ( -3.12 to 4.32$)$, favouring the intervention group. The corresponding incremental QALYs was 0.027 (0.004-0.051), favouring the intervention group.

\section{Cost-effectiveness analysis}

The intervention was more effective and more costly for both pressure ulcer size and QALYs. The ICER at 12 weeks was INR 2306 (USD 130) per additional $\mathrm{cm}^{2}$ reduction in pressure ulcer size, and INR 44915 (USD 2523) per QALY gained (Table 5). The results of bootstrapping incremental costs and outcomes in the intervention versus control groups are graphically displayed in scatter plots (Figures 1a and b). In terms of pressure ulcer healing, the intervention had a $20 \%$ chance of being cost saving and effective; for QALY, it had a $41 \%$ chance of being cost saving and effective. Figure 2 illustrates the results of the CEAC for pressure ulcer size and QALYs. It demonstrates that there is a $59 \%$ probability of being cost-effective at a willingness-to-pay threshold of INR 9000 (USD 506) for each additional $1 \mathrm{~cm}^{2}$ that their pressure ulcers heal compared with usual care (Figure 2a). More importantly, using a multi-attribute measure of health-related quality of life, it indicates that there is an $87 \%$ probability of being cost-effective at a threshold ratio of INR 331650 (USD 18 632)/QALY gained, that is, less than 3 times per capita GDP.

\section{Sensitivity analysis}

The sensitivity analysis examined the effect of removing the productivity costs (that is, lost income) from the overall costs (Table 5). This analysis showed that removal of the productivity cost increased the 

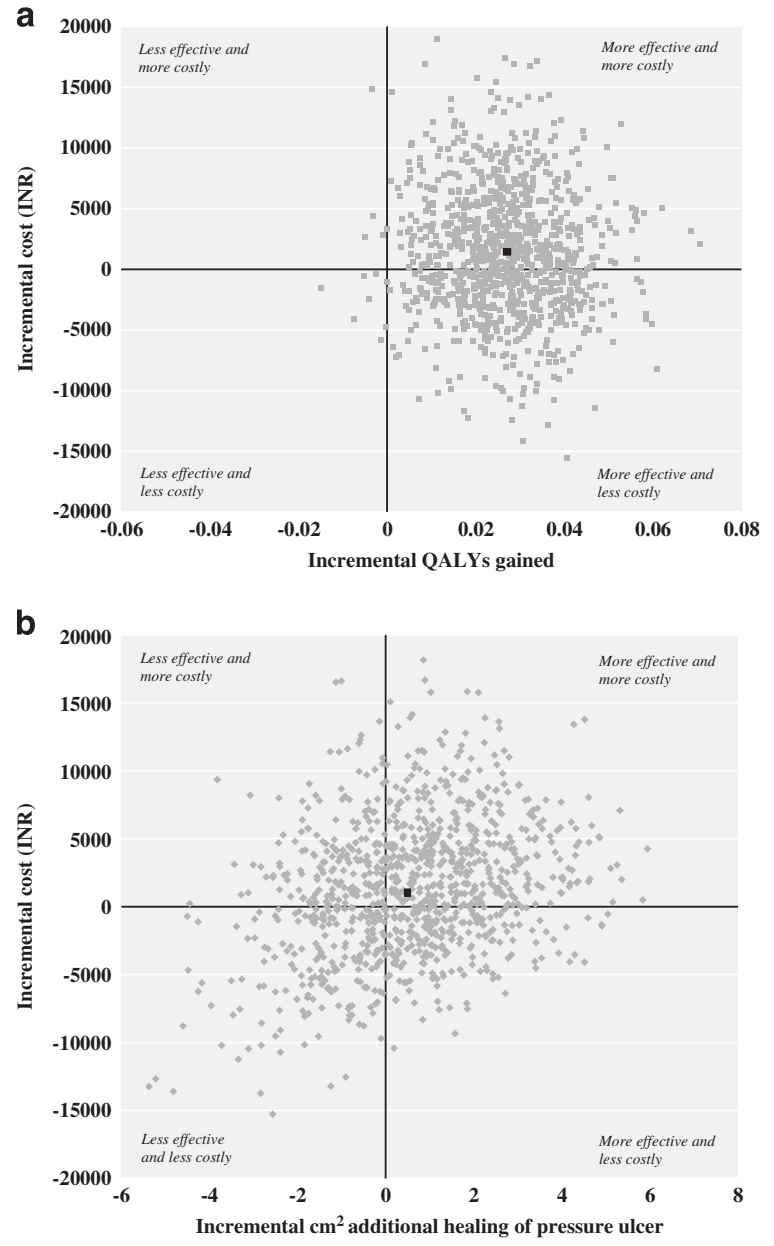

Figure 1 Incremental cost-effectiveness planes of $n=1000$ bootstrap replicates (grey dots) and point estimate (black dot) for (a) incremental cost and QALYs gained; (b) incremental cost and per $\mathrm{cm}^{2}$ additional healing of pressure ulcer.

mean ICER from INR 44915 (USD 2523) to INR 63242 (USD 3553) per QALY gained. Whilst the mean ICER is sensitive to the removal of productivity costs, there is still an $87 \%$ probability (Figure 2) of being cost-effective at the threshold ratio of INR 331650 (USD 18632) per QALY gained.

\section{DISCUSSION}

To our knowledge, this is the first economic evaluation to investigate a low cost treatment option for the management of pressure ulcers in people with SCI living in LMICs. Economic analyses of intervention studies are becoming a priority and important component of research for decision and policy makers. ${ }^{20}$ They are particularly important for LMICs where resources are limited. Our economic evaluation shows that the cost of delivering the telephone support over 12 weeks was INR 2110 (USD 119) per patient. These costs were partially offset by lower healthcare costs and lower productivity losses in the intervention participants compared with control. Overall, telephone-based support was more effective even though more costly with respect to QALYs and pressure ulcer healing outcomes than the usual standard care. The incremental cost-effectiveness ratio of INR 44915 (USD 2523) per QALY gained, indicates that this intervention has a very high probability of being cost-effective based on the willingness-to-pay threshold of less than three times GDP per QALY gained.
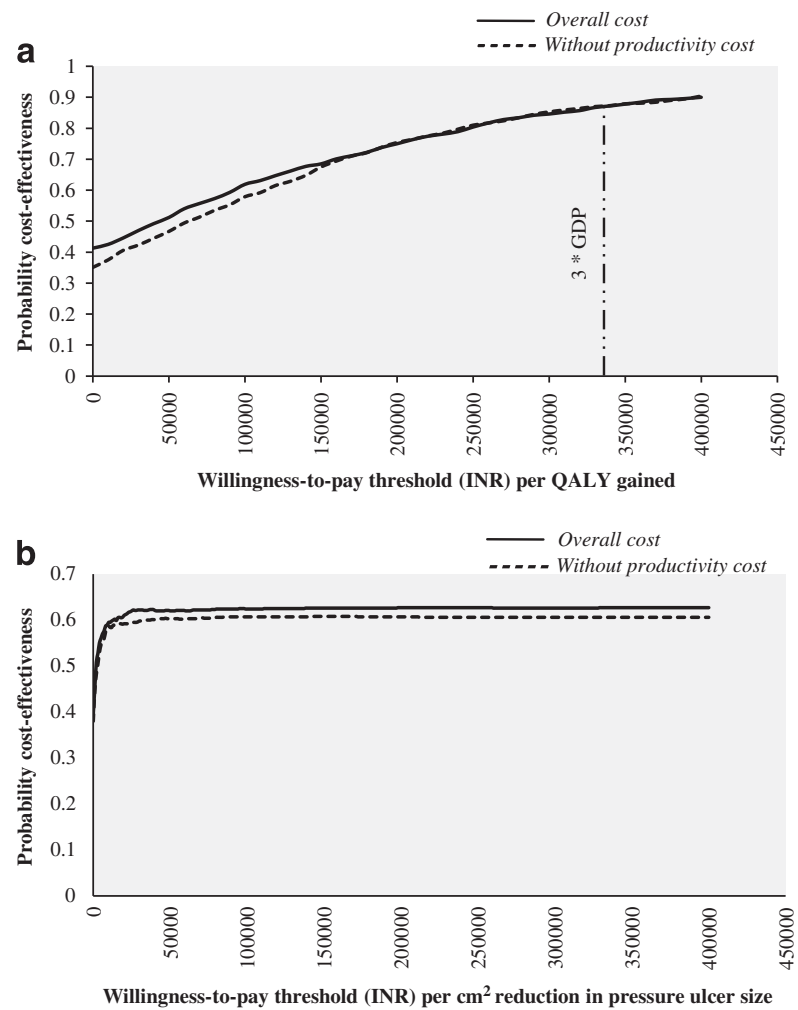

Figure 2 Cost-effectiveness acceptability curve for (a) QALYs, and (b) Pressure ulcer size $\left(\mathrm{cm}^{2}\right)$. The black line in each figure represents the costeffectiveness acceptability curve for overall cost and the black dotted line represents the cost-effectiveness acceptability curve for overall cost excluding productivity cost for India in the year 2015.

Our study has several strengths. First, the study protocol was prospectively registered and published, ${ }^{12}$ and the economic evaluation was reported in compliance with the Consolidated Health Economic Evaluation Reporting Standards guidelines. ${ }^{21}$ Second, this study was conducted alongside an randomised controlled trial ${ }^{8}$ with costs and outcomes drawn directly from the study participants. The randomised controlled trial was multi-centred across two countries avoiding potential issues associated with single site studies. Third, we took a societal perspective which is the relevant perspective in countries like India and Bangladesh where most healthcare costs are borne by patients. In addition we have used a recently published Sri Lankan valuation of the EQ-5D $\mathrm{D}^{13,14}$ to derive utilities for the cost-utility analysis. We believe this is more appropriate to our setting than the UK valuation, ${ }^{22}$ which has been used in previously published economic evaluations from LMICs.

Our study used the EQ-5D tool to measure health-related quality of life. The lowest possible utility value using the Sri Lankan valuation of this instrument, is -0.75 , representing a health state 'worse than death'. As our participants had severely impaired mobility and poor health, their average utility scores were negative; however mean utility scores improved more in the intervention than in control. The underlying mechanism is unclear, but it is highly likely that the telephone support could have had broader benefits than just on pressure ulcer healing. We observed improvement in every domain of the EQ-5D except mobility, with $82 \%$ of intervention participants showing improvement in one or more domains of the EQ-5D, compared with only $67 \%$ of the control group showing improvement. 
Our analysis relied on estimating costs associated with health care utilisation. However, we may have underestimated some of the costs because we used national data sources to estimate the cost of some items. In addition, we did not include the productivity losses associated with prolonged bed rest. Prolonged bed rest is a key aspect of the management of pressure ulcers and limits participants' ability to work. Our failure to include the costs associated with prolonged bed rest is unlikely to have systematically biased our overall cost because bed rest would have been an aspect of management for participants in both arms of the study. Of course, we only measured outcomes at 12 weeks when the intervention ceased and therefore do not know the long-term cost-effectiveness of the intervention.

While, the results for the primary outcome (size of pressure ulcer) indicate some uncertainty about whether telephone-based support reduces the size of pressure ulcers, the economic evaluation demonstrated that telephone-based management is a cost-effective intervention. It also has a high probability of being cost saving. These findings should be of interest to policy makers in LMICs and not-for-profit organisations working in this area. To date effort is being directed at immediate medical care following SCI in LMICs. However, this effort is somewhat wasted if the problems of pressure ulcers are not addressed. Although we have very little data on the incidence of pressure ulcers or mortality in people with SCI from LMICs, few would dispute the claim that pressure ulcers are an insidious scourge, leading cause of death, and source of widespread misery. The telephone-based support studied in this trial is a relatively simple intervention to roll out. Of course, advice over a telephone alone will not solve the complex problem of pressure ulcers. However, this intervention is being used in a context where people with pressure ulcers receive very little medical assistance and no support relate to their pressure ulcers is available. Our findings strongly suggest this simple intervention provides good value for money, and may be an intervention worth rolling out across all LMICs for people with pressure ulcers secondary to SCI.

\section{DATA ARCHIVING}

There were no data to deposit.

\section{CONFLICT OF INTEREST}

The authors declare no conflict of interest.

\section{ACKNOWLEDGEMENTS}

The authors thank and acknowledge the contribution of Prof. Kirsten Howard for commenting on the draft of the manuscript and Dr Sanjeewa Kularatna for providing the algorithm for mapping the EQ-5D-5L. The authors acknowledge the assistance of the project coordinators (Mr Jaspreet Singh Sethi,

Md Abdullah and Mr Ranjit Roy) at the study sites, the participants and staff who assisted in recruiting participants.
1 Chhabra HS, Arora M. Demographic profile of traumatic spinal cord injuries admitted at Indian Spinal Injuries Centre with special emphasis on mode of injury: a retrospective study. Spinal Cord 2012; 50: 745-754.

2 Lee BB, Cripps RA, Fitzharris M, Wing PC. The global map for traumatic spinal cord injury epidemiology: update 2011, global incidence rate. Spinal Cord 2014; 52: $110-116$.

3 National Spinal Cord Injury Statistical Centre. Spinal Cord Injury Model Systems 2013 Annual Report Complete Public Version. Birmingham, UK, 2013. p.13-89.

4 Hossain MS, Rahman MA, Herbert RD, Quadir MM, Bowden JL, Harvey LA. Two-year survival following discharge from hospital after spinal cord injury in Bangladesh. Spinal Cord 2016; 54: 132-136.

5 World Health Organization (WHO) and International Spinal Cord Society (ISCoS). International perspectives on spinal cord injury. Bickenbach J, Officer A, Shakespeare T, von Groote P, WHO, ISCoS (eds). Malta, 2013.

6 National Pressure Ulcers Advisory Panel, European Pressure Ulcers Advisory Panel and Pan Pacific Pressure Injury Alliance. Prevention and Treatment of Pressure Ulcers: Quick Reference Guide. Osborne Park: Australia. 2014: Cambridge Media; 2014. Available at: http://www.npuap.org/resources/educational-and-clinical-resources/prevention-and-treatment-of-pressure-ulcers-clinical-practice-guideline/ (Accessed 10 December 2016).

7 Houghton PE, Campbell KE, CPG Panel. Canadian Best Practice Guidelines for the Prevention and Management of Pressure Ulcers in People with Spinal Cord Injury. A Resource Handbook for Clinicians, 2013. Available at http://www.onf.org (accessed 5 June 2016).

8 Arora M, Harvey LA, Glinsky JV, Chhabra HS, Hossain S, Arumugam N et al. Telephonebased management of pressure ulcers in people with spinal cord injury in low- and middle-income countries: a randomised controlled trial. Spinal Cord 2016; 55: 141-147.

9 Cereda E, Klersy C, Andreola M, Pisati R, Schols JM, Caccialanza R et al. Costeffectiveness of a disease-specific oral nutritional support for pressure ulcer healing. Clin Nutr 2015; 36: 246-252.

10 Demarre L, Van Lancker A, Van Hecke A, Verhaeghe S, Grypdonck M, Lemey J et al. The cost of prevention and treatment of pressure ulcers: A systematic review. Int J Nurs Stud 2015; 52: 1754-1774.

11 Palfreyman SJ, Stone PW. A systematic review of economic evaluations assessing interventions aimed at preventing or treating pressure ulcers. Int J Nurs Stud 2015; 52: 769-788.

12 Arora M, Harvey LA, Hayes AJ, Chhabra HS, Glinsky JV, Cameron ID et al. Effectiveness and cost-effectiveness of telephone-based support versus usual care for treatment of pressure ulcers in people with spinal cord injury in low-income and middle-income countries: study protocol for a 12-week randomised controlled trial. BMJ Open 2015; 5: e008369.

13 Kularatna S, Chen G, Byrnes J, Scuffham PA. Mapping Sri Lankan EQ-5D-3L to EQ-5D-5L value sets. Value Health Reg Issues 2017; 12: 20-23.

14 Kularatna S, Whitty JA, Johnson NW, Jayasinghe R, Scuffham PA. Valuing EQ-5D health states for Sri Lanka. Qual Life Res 2015; 24: 1785-1793.

15 The Organisation for Economic Co-operation and Development (OECD). Purchasing power parities (PPP) (indicator), 2016. Available at http://dx.doi.org/10.1787/ 1290ee5a-en (accessed 4 October 2016).

16 Briggs $\mathrm{AH}$. Statistical approaches to handling uncertainty in health economic evaluation. Eur J Gastroenterol Hepatol 2004; 16: 551-561.

17 Glick HA, Briggs AH, Polsky D. Quantifying stochastic uncertainty and presenting results of cost-effectiveness analyses. Expert Rev Pharmacoecon Outcomes Res 2001; 1: 25-36.

18 Commission on Macroeconomics and Health. Macroeconomics and health: Investing in Health for Economic Development. World Health Organization: Geneva, Switzerland. 2001.

19 International Monetary Fund. World Economic Outlook Database, 2015. Available at http://www.imf.org/external/index.htm (accessed 4 October 2016).

20 Sculpher MJ, Claxton K, Drummond M, McCabe C. Whither trial-based economic evaluation for health care decision making? Health Econ 2006; 15: 677-687.

21 Husereau D, Drummond M, Petrou S, Carswell C, Moher D, Greenberg D et al. Consolidated Health Economic Evaluation Reporting Standards (CHEERS)- explanation and elaboration: a report of the ISPOR Health Economic Evaluation Publication Guidelines Good Reporting Practices Task Force. Value Health 2013; 16: 231-250.

22 Dolan P. Modeling valuations for EuroQol health states. Med Care 1997; 35: 195-198. 